\title{
Medidas da Umidade Relativa do Ar em um Ambiente Fechado
}

\author{
(Relative Air Humidity Measurements in a Closed Environment) \\ Eden V. Costa \\ Instituto de Física, Universidade Federal Fluminense \\ Boa Viagem, 24210-340, Niterói, RJ, Brasil \\ Eden@if.uff.br
}

Recebido em 15 de abril, 2003. Aceito em 08 de setembro, 2003.

\begin{abstract}
Umidade do ar é o vapor d'água presente na atmosfera. Neste trabalho medimos a umidade relativa do ar em um ambiente fechado onde a temperatura foi mantida constante. Nestas condições, a umidade cresce até o vapor d'água tornar-se saturado. Neste instante, a umidade é máxima. O aparato experimental utilizado consiste de recipiente fechado de vidro, higrômetro, termômetro e relógio. Trata-se, portanto, de um experimento simples, possível de ser realizado em um laboratório didático e capaz de preencher a lacuna dos livros de texto de física, que, em geral, negligenciam este tópico.
\end{abstract}

\begin{abstract}
Air humidity is the water vapor existing in the atmosphere. In this paper it is presented measurements of the relative air humidity inside a closed container where temperature was kept constant. Under these conditions, humidity increases until water vapor becomes saturated. At this moment, humidity reaches its maximum value. The experimental set includes: a closed glass container, a hygrometer, a thermometer and a chronometer. Thus, it is a simple experiment, which is possible to be reproduced in a general physics laboratory and used as a complement to textbooks that do not include this topic.
\end{abstract}

\section{Introdução}

Nos livros didáticos de física em uso atualmente, não consta o tema umidade relativa do ar. Curiosamente, diariamente, o serviço de meteorologia divulga a previsão do tempo onde são dados os valores de temperatura e umidade relativa do ar. Sendo assim, percebemos ser conveniente desenvolver este tema, presente em nosso dia-a-dia, mas ausente nos livros didáticos de física atualmente adotados.

Evaporação é a transição de fase líquido $\rightarrow$ vapor (vaporização) em uma temperatura menor do que a de ebulição. No processo são atuantes as moléculas da interface, caracterizando-se, portanto, como um fenômeno de superfície. A pressão $p$ exercida pelo vapor sobre a massa líquida, chama-se pressão de vapor.

Considere um ambiente fechado onde há água em evaporação. Quando o sistema líquido-vapor atingir o equilíbrio, a pressão de vapor será máxima $P$. Dizemos então que o vapor d'água está saturado. A Tabela 1 mostra a pressão máxima de vapor d'água saturado para alguns valores de temperaturas [1].

Umidade relativa do ar (grau higrométrico do ar) é a razão entre a pressão de vapor d'água na atmosfera e a pressão de vapor d'água saturado:

$$
U R=\frac{p}{P}
$$

Assim, em um ambiente saturado, a umidade relativa do ar é igual a 1. A Tabela 2 mostra a densidade do vapor d'água saturado para alguns valores de temperaturas.

Considere um ambiente onde $m$ é a massa de vapor d'água presente na sua atmosfera e $M$ a massa de vapor d'água necessária para saturá-lo. A umidade relativa do ar é igual a

$$
U R=\frac{m}{M}
$$

A massa que se evapora na unidade de tempo (taxa de evaporação) é dada por [2]

$$
\frac{d m}{d t}=k \frac{A(P-p)}{p_{\text {ext }}},
$$

em que $k$ é uma constante característica do líquido, $A$ é a área da superfície livre do líquido e $p_{\text {ext }}$ é a pressão externa ao líquido.

A temperatura é diretamente proporcional a pressão máxima de vapor $P$ (Tabela 1 ). Sendo assim, quanto maior a temperatura, maior a taxa de evaporação.

Durante a evaporação, a concentração de vapor $p$ junto à superfície líquida cresce e, como conseqüência, diminui a taxa de evaporação. 
Tabela 1. Pressão máxima do vapor d'água saturado para alguns valores de temperatura.

\begin{tabular}{lcccccccc}
\hline $\mathrm{T}\left({ }^{\circ} \mathrm{C}\right)$ & 19 & 21 & 24 & 27 & 30 & 33 & 36 & 39 \\
\hline $\mathrm{P}$ (Torr) & 16,5 & 18,7 & 22,4 & 26,7 & 31,8 & 37,7 & 44,6 & 52,5 \\
\hline
\end{tabular}

Tabela 2. Densidade do vapor d'água saturado para alguns valores de temperatura.

\begin{tabular}{lcccccccc}
\hline $\mathrm{T}\left({ }^{\circ} \mathrm{C}\right)$ & 19 & 21 & 24 & 27 & 30 & 33 & 36 & 39 \\
\hline$\rho\left(\mathrm{g} / \mathrm{m}^{3}\right)$ & 16,4 & 18,4 & 21,9 & 25,9 & 30,5 & 35,8 & 41,9 & 48,4 \\
\hline
\end{tabular}

\section{Teoria}

Vamos considerar a evaporação da água em um ambiente cuja pressão externa é constante. Valendo-se da proporcionalidade entre a pressão e a massa de vapor, a equação (3) torna-se

$$
\frac{d m}{d t}=B(M-m)
$$

$B$ é constante. Podemos escrever

$$
\frac{d m}{(M-m)}=B d t
$$

Por integração obtemos que

$$
-\ln (M-m)=B t+C .
$$

Vamos considerar a umidade relativa do ar inicial, tal que a massa de vapor d'água em $t=0$ é $m_{0}$. Assim,

$$
-\ln \left(M-m_{0}\right)=C
$$

Deste modo,

$$
\begin{gathered}
\ln \left(\frac{M-m}{M-m_{0}}\right)=-B t \\
m=M-\left(M-m_{0}\right) \exp (-B t) .
\end{gathered}
$$

Por exemplo, se a evaporação ocorrer em um ambiente cuja umidade relativa do ar inicial for igual a 0,62 $\left(m_{0}=0,62 \mathrm{M}\right)$, então a equação (9) torna-se

$$
U R=1-(0,38) \exp (-B t) .
$$

A equação (10) mostra que a umidade relativa do ar cresce exponencialmente com o tempo.

Alguns outros fenômenos físicos são descritos por equação semelhante à equação (10). Por exemplo:

a) o crescimento da velocidade de uma gota de chuva.

b) o crescimento da carga elétrica armazenada no capacitor em um circuito $\mathrm{RC}$,

c) o crescimento da corrente elétrica em um circuito RL.

Uma vez que, na equação (10), a dependência é exponencial, não é possível determinar, exatamente, o intervalo de tempo necessário para a saturação do vapor. Como o expoente é adimensional, o inverso da constante $B$ tem dimensão de tempo. Vamos considerar o caso particular em que $B t=1$. Nesta condição, temos que

$$
U R=1-(0,38) \exp (-1)
$$

$$
U R=0,86
$$

Assim, o intervalo de tempo igual a $(1 / B)$ é o necessário para que a umidade relativa do ar atinja 0,86 .

\section{Aparato Experimental e resulta- dos}

Nossa intenção foi medir o intervalo de tempo necessário para que o vapor d'água presente em um ambiente fechado sob temperatura constante torne-se saturado. Para isso, seguimos a sugestão apresentada por Preston [3]. Construímos três recipientes de vidro com volumes iguais a um litro. No seu interior colocamos um termômetro, um higrômetro, um relógio e 3,0 $\mathrm{ml}$ de água. A área da superfície livre da água em cada um deles é igual a: $42 \mathrm{~cm}^{2}, 84 \mathrm{~cm}^{2}$ e $168 \mathrm{~cm}^{2}$ (Fig. 1).

Os recipientes foram mantidos sob temperatura constante e igual a $21^{\circ} \mathrm{C}$. Nesta temperatura, a massa de vapor d'água necessária para saturar um ambiente cujo volume é um litro é 18,4 mg (tabela 2). A umidade relativa do ar inicial nos recipientes é igual a 0,62. Sendo assim, a massa inicial de vapor d'água em cada um deles é: 0,62 x 18,4mg $=11,4 \mathrm{mg}$.

Portanto, para saturar o vapor d'água do ambiente, faltam 7,0 mg. Logo, enquanto a umidade relativa do ar varia entre 0,62 e 1,0, a pressão externa ao líquido varia entre a normal (760 Torr) e 767 Torr. Este aumento de pressão é menor do que $1,0 \%$, o que justifica a premissa inicial quando estabelecemos ser constante a pressão externa ao líquido.

O sistema foi monitorado. A variação da umidade relativa do ar em função do tempo, para o recipiente cuja área da superfície livre da água é igual a $168 \mathrm{~cm}^{2}$ pode ser vista na Fig. 2. 


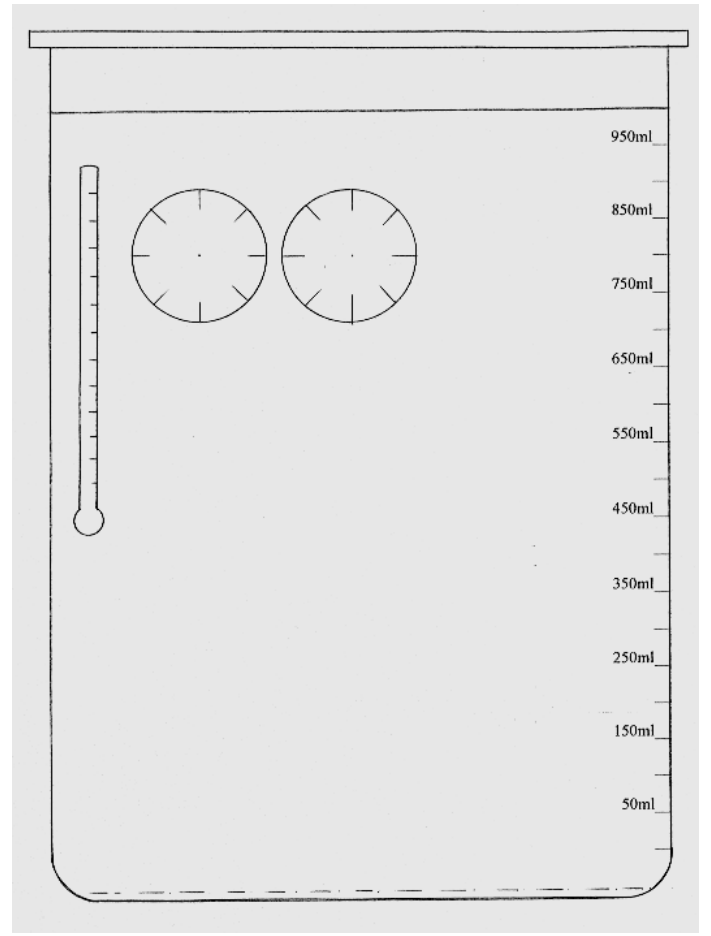

Figura 1. Recipiente fechado de vidro com volume igual a um litro. Em seu interior há um termômetro, um higrômetro, um relógio e $3,0 \mathrm{ml}$ de água. A área da base pode ser igual a: $42 \mathrm{~cm}^{2}, 84 \mathrm{~cm}^{2}$ ou $168 \mathrm{~cm}^{2}$.

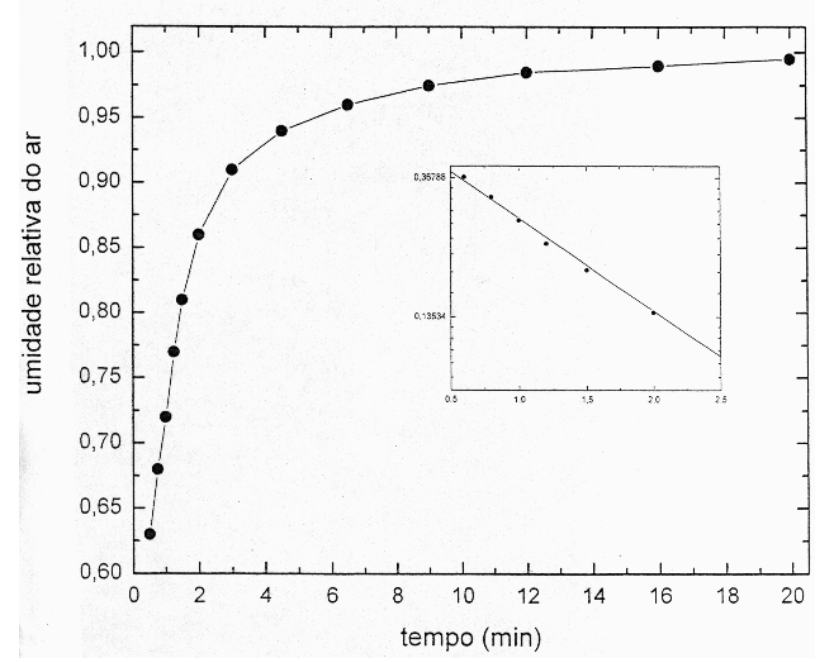

Figura 2. Umidade relativa do ar em função do tempo em um ambiente fechado com volume igual a um litro e sob temperatura constante $\left(21^{\circ} \mathrm{C}\right)$. A umidade relativa do ar inicial é 0,62 . A área da superfície livre do líquido é igual a $168 \mathrm{~cm}^{2}$. O intervalo de tempo necessário para que a umidade relativa do ar atinja 0,86 é de $(2,00$ $\pm 0,05)$ minutos. Os valores medidos (círculos) estão conectados por segmento de reta. Em destaque o gráfico em papel mono-log.

Os valores medidos do intervalo de tempo necessário para a umidade relativa do ar atingir 0,86 podem ser vistos na Tabela 3.

Tabela 3

\begin{tabular}{ccccc}
\hline área da superfície livre da água & $\left(\mathrm{cm}^{2}\right)$ & 168 & 84 & 42 \\
\hline $\begin{array}{c}\text { intervalo de tempo necessário para a } \\
\text { umidade relativa do ar atingir 0,86 }\end{array}$ & $(\mathrm{min})$ & $(2,00 \pm 0,05)$ & $(5,50 \pm 0,05)$ & $(13,00 \pm 0,05)$ \\
\hline
\end{tabular}

\section{Conclusões}

Este trabalho é uma aplicação da equação (10) em um ambiente fechado onde, inicialmente, a umidade relativa do ar é igual a 0,62 e a pressão atmosférica é normal (760 Torr). A temperatura do ambiente manteve-se constante e igual a $21^{\circ} \mathrm{C}$. Sendo assim, foi possível verificar:

(1) a dependência entre o intervalo de tempo necessário para a saturação do vapor e a área da superfície livre do liquido. Fato costumeiro em nosso cotidiano, na secagem de roupas. Por isso, estendemos a roupa para que seque rapidamente; (2) a dependência entre a umidade relativa do ar e a taxa de evaporação. Por isso, o vento influi na taxa de evaporação, ao dissipar o vapor d'água próximo à superfície líquida. Desta forma, ele diminui a umidade do ar, facilitando a evaporação da água restante.

É comum pensar que o único papel dos condicionadores de ar é refrigerar, mas eles têm um outro papel importante: reduzir a umidade relativa do ar. Por isso pinga água desses aparelhos.

Os resultados mostram ser viável a utilização deste ex- perimento em um laboratório didático. Trata-se, portanto, de um experimento simples, de fácil manuseio, e, capaz de preencher a lacuna existente nos livros de física básica, que, em geral, não abordam este tema.

\section{Agradecimentos}

Agradeço a minha esposa e companheira Nadia Regina C. Costa e a meu filho e amigo Tales C. Costa, pela colaboração, dedicação e afinco na tomada das medidas.

\section{Referências}

[1] G. W. C. Kaye, Tables of Physical and Chemical Constants, Longman, 1995.

[2] D. E. Gray, American Institute of Physics Handbook, McGraw-Hill Book Company, 1997.

[3] D. W. Preston, Experiments in Physics (Laboratory Manual), John Wiley \& Sons, 1994. 